\section{Circuit of incoherence: brazilian society suffers from disruption of dramatic personalities}

\author{
Dr. Fabiano de Abreu Agrela Rodrigues ${ }^{1}$ \\ deabreu.fabiano@gmail.com
}

\begin{abstract}
Denialism, hysteria, the need to draw attention, narcissism are among the most talked about behaviors nowadays. Taking into account that Brazilian society is considered the most anxious in the world, all these behaviors derived from the culture that resulted in this constant and intensified anxiety are triggering disturbances that are not necessarily genetic in origin, but that may be part of genetics. Brazil passing to future generations. Our behaviors create tracks that are passed from generation to generation. This article aims to determine that we are in fact living in the stage of dramatic personalities that trigger disorders and syndromes that are making society ill, raising anxiety even more and generating generalized antisocial behavior.
\end{abstract}

Keywords: disorders; society; brain; media; emotions.

\footnotetext{
1 Doctorate in Neurosciences from UniLogos in Florida, Doctorate and Master in Health Sciences in the areas of Psychology and Neurosciences from EBWU in Florida, with the title recognised by the New University of Lisbon; Master in Psychoanalysis from the Instituto e Faculdade Gaio/Unesco; Postgraduate degree in Neuropsychology from Cognos in Portugal; Postgraduate degree in Neuroscience, Neuroscience applied to learning, Neuroscience in behaviour, neurolinguistics and Anthropology from Faveni do Brasil; Advanced Specializations in Clinical Nutrition at TrainingHouse in Portugal, The electrical Properties of the Neuron, Neurons and Networks, neuroscience at Harvard in the United States; Bachelors in Neuroscience and Psychology at EBWU in Florida, Technologist in Anthropology at UniLogos in Florida/ title recognized in Asia and United Kingdom/ ASIC; Bachelor in Biology and also in History at Faveni in Brazil; Specializations in Artificial Intelligence at IBM and Python programming at USP; MBA in positive psychology at PUC.
} 


\section{Circuito da incoerência: a sociedade brasileira sofre perturbação de personalidades dramáticas}

\section{RESUMO}

Negação, histeria, necessidade de chamar atenção, narcisismo estão entre os comportamentos mais comentados atualmente. Levando em conta que a sociedade brasileira é considerada a mais ansiosa do mundo, todos esses comportamentos derivados da cultura que resultaram nessa ansiedade constante e intensificada estão desencadeando distúrbios que não são necessariamente de origem genética, más que podem ser parte da genética. O Brasil passando para as gerações futuras. Nossos comportamentos criam rastros que são passados de geração em geração. Este artigo tem como objetivo constatar que estamos, de fato, vivendo na fase de personalidades dramáticas que desencadeiam transtornos e síndromes que estão adoecendo a sociedade, aumentando ainda mais a ansiedade e gerando comportamentos antissociais generalizados.

Palavras-chave: transtornos; sociedade; cérebro; meios de comunicação; emoções.

Artículo recibido: 02 enero 2022 Aceptado para publicación: 28 enero 2022 Correspondencia: deabreu.fabiano@gmail.com Conflictos de Interés: Ninguna que declarar 


\section{INTRODUCTION}

To better understand and seek a solution to social behavior and its criticisms, behavior in the form of personality was analyzed, indicating the most evidence such as excessive anxiety, selfishness, narcissism, egoagacentrisionism of propacy, fake news or Solidarity to "Call Attention", Exacerbated Pride, Extreme Vanity, Lack of Education, Lack of Compassion, Need for Fame without the Argument And Coherence, Investment in Buying Likes And Followers on Social Networks With A "False Story", Exhibitionism, ostentation, inconsistency in arguments and arrogance. All these are derived from pathological narcissism and the need to seek happiness as if this increasingly unattainable location.

Histrionic personality disorder (PHD) is a single modern category in diagnostic classifications that preserves a derivative of the ancient concept of hysteria of psychoanalysis. HPT is chosen by a generalized pattern of excessive emotionality and search for attention. Narcissistic personality disorder (NPT) is a generalized pattern of grandeur, need for adulation and lack of empathy.

Borderline personality disorder (PLD) is a generalized pattern of instability in transference, self-image, mood and behavior, as well as hypersensitivity to the possibility of rejection and abandonment. On the other hand, antisocial personality disorder (ASD) is a generalized pattern of neglect of the consequences and rights of others. Finally, borderline personality disorder (BPD) is characterized by a generalized pattern of instability and hypersensitivity in interpersonal referrals, instability in self-image, extreme fluctuations in mood and impulsivity.

These disorders are just some that are part of the dramatic personality disorders, characterized by dramatic, emotional or erratic appearance and all are linked to narcissism and the need for fe $\mathrm{m}$ and lib, the need to be seen and / or noticed as a social positioning for conquest, reward, arise and reproduction. Recalling that our instincts are related to the maintenance of the species as well as all living organisms on the planet, this article aims to demonstrate that social behavior and subtle cults related to what is adapted and consequences that can be crucial to the well-being of society.

\section{BEHAVIORS}

Dramatic behaviors that reflect the need to release neurotransmitters that bring good sensations, such as dopamine and serotonin, have anxiety as a pending, at the same time 
in mó t cam satisfreas que queéção más This consistent obligation alters the functioning of neurotransmitters causing structural changes even if they seem inconsistent.

\subsection{Anxiety}

Studies have already revealed anxiety cells in the hippocampus, a region that regulates memory. These cells are produced in the hypothalamus, a region of the brain that also regulates the hormones (dopamine and serotonin) that control emotions. The impact of anxiety on the brain is due to the combination of cortisol, noradrenaline and adrenaline. As an outbreak effect, while an amygdala seeks to identify the danger, these neurotransmitters function as a defense mechanism through reaction. This brings more blood to the muscles, accelerating the heart and bringing more air to the lungs.

The cortisol hormone is released by the adrenal gland in response to increased blood levels of adrenocorticotropic hormone $(\mathrm{ACTH})$, released by the anterior pituitary gland in response to the $\mathrm{CRH}$ stytronium. Hypothalamic neurons that secrete $\mathrm{CRH}$ are regulated by the amygdala and hippocampus.

When the central nucleus of the amygdala is activated, it interferes with the HPA axis and the stress response is emitted, and inappropriate activation has been related to anxiety disorders. The hippocampus contains glucocorticoid receptors that are activated by cortisol, and with high levels of circulating cortisol, participates in the regulation by feedback of the HPA axis, inhibiting the release of CRtis AC. Continuous exposure to cortisol in periods of chronic stress can lead to dysfunction and death of hippocampal neurons (BEAR; CONNORS; PARADISO, 2006, p. 675).

LE DOUX (2001), an article that the hippocampus may present flaws in its ability to control the release of stress hormones and perform its routine functions. Stress also influences the ability to induce long-term potentiation in the hippocampus, which probably explains why memory failure occurs. "High prefrontal cortex activity has also been reported in anxiety disorders."

Therefore, in summary, an amygdala and the hippocampus regulate the HypothalamicHypophyseal-adrenal axis and the response to stress in a coordinated way, both with the hyperactivity of the amygdala, related in elecon of mymoscientías from mesicos to mesicomentó of the hippocampus, which participates in the storage of conscious memories during a situation of traumatic learning. 


\subsection{Inconsistency}

Most patterns can bring an impression of inconsistency, realizing the lack of intelligence due to the consequences of behavior. But there is an emotion-reason relationship that interferes, where emotion is left over impairs coherence, influenced by emotional need, impairing communication between the prefrontal cortex and the limbic system

\subsection{Thank your neurotransmitters and need for reward}

Serotonin 5-HT is a very important substancein the neurochemical study of anxiety, both the blockade of its receptors and the blockade of its synthesis, produces anxiolytic effects. Studies show that a 5-HT plays a double role in the regulation of anxiety, being anxiogenic in the amygdala and anxiolytic in dorsal periaqueductal gray matter (MCPD). The amygdala seems to have the function of assessing the degree of amoech to then instruct executive structures as to the type of defense reaction to be programmed. The MCPD should be triggered only in cases of imminent danger.

Therefore, it makes sense that serotonergic neuronal systems inhibit a PDCM, while facilitating the processing of defense information in the amygdala. From this point of view, the dual role of 5-HT can be considered as having an adaptive value (AFONSO, et. Al. 1997)

Selective serotonin reuptake inhibitors (SRIs) prolong the action of serotonin released on their receptors, inhibiting their reuptake. The effect seems to be due to an adaptation of the nervous system to high levels of serotonin brain and one of the adaptive responses to SSRIs is an increase in glucocorticoid receptors in hippocamposal retroneurosis

Research still shows another neurotransmitter because in anxiety processes, gammaaminobutyric acid (GABA), the main inhibitory neurotransmitter of the Central Nervous System (CNS), present in almost all regions of the brain, embraces reconforms to concentrations.

For AFONSO and colaborabores (1997), the relationship between GABA and anxiety is evidenced in the fact that all known anxiolytics facilitate their action. Its anxiolytic effect seems to be to reduce the functioning of neuronal groups of the limbic system (SL), including the amygdala and hippocampus, responsible for the integration of defense reactions against damage threats, only by damage,

When COMBINED with the receiver, GABA changes a conformation AND This deformation is transmitted to the Chlorine channel $\left(\mathrm{Cl}^{-}\right)$, Opening it. With this, $\mathrm{Cl}^{-}$ 
penetrate ionsof the cell, where its concentration is lower than the external one. There is then a hyperpolarization of the postsynaptic membrane that inhibits the firing of the postsynaptic neuron because it hinders the depolarization of its membrane, necessary for gerasoçãoner, 1997). LE DOUX (2001) states that some drugs induce anxiety by acting on the alteration of synaptic transmission in the brain, including benzodiazepines, which stimulate the action of GABA, thus suppressing activities stress.

Dopamine seems to be fundamental in mediating reward effects. Dopaminergic neurons project from the ventral tegmentary area of the midbrain to many areas of the brain through the medial prosencephalic bundle. In addition, drugs that cause chemical dependence increase the effectiveness of dopamine and cause its release into the coreacumbens, demonstrating the role of this neurotransmitter in the mechanisms of reward and / or pleasure.

The induction of joy causes activation of the basal ganglia, including the ventral striatum and the putamen. The basal ganglia present a rich innervation of dopaminergic neurons of the mesolimbic system, closely related to the generation of pleasure, and the dopaminergic system of the ventral striated nucleus. Dopamine acts independently, using opioid and GABAergic receptors in the ventral striatum, amygdala and orbitofrontal cortex, also related to affective states (such as sensory pleasure), while outsensors are generated in the (BURGDORF; PANKSEPP, 2006).

In addition to the components, there are studies involving the participation of neurotransmitters in the modulation of anger and aggression. Serotonin is one of the neurotransmitters involved in this regulation, which can be easily suggested, since the location of serotonergic neurons in the raphe of the brainstem is known, associates and brain ra in the ramias and serotonin is one of the neurotransmitters involved in this negotiation, which can be easily suggested. This association can be reinforced by studies conducted with knockout mice for 5-HT receptors. These receptors are involved in the raphe nuclei, amygdala, periaqueductal gray matter and basal ganglia.

\subsection{Common physiology of reason and emotion}

There are four structures connected in Papez's circuit: hypothalamus, anterior nucleus of the thalamus, cingulate gyrus and hippocampus. Over time, the orbitofrontal and midfrontal cortexes were also added to this group, in the prefrontal area, parahippocampal gyrus and subcortical groups. The groupings include amygdala, septal area, median 
nucleus of the thalamus, basal nuclei of the forebrain and trunk formations (CONSENZA, 1990).

The tendency to an excessively emotional reaction to rejection can be attributed to a defect in a group of neurotransmitters called catecholamines, as the main ones are dopamine, adrenaline and noradrenaline.

An important structure in emotion / reason integration is the insula, which is activated during an induction of memories of moments experienced by an individual that provoke a special sensation, whether raquale, tri fes. However, the insula is not activated when the same sensation is provoked in the same individual by a film, for example, suggesting that such a structure is involved in the aspects of evaluation of oue of emoation expression. The amygdala receives the substantial amount of stimuli from the temporal areas associated with vision, participating in the formation of memories through hippocampal circuits or striated circuits. Sensory impressions (such as vision, hearing and other somatosensory information) converge, through the frontal orbit cortex (COF), to the ventromedial prefrontal cortex (CPFVM), from where the information is precial déal synthesis and inferior-lateral prefrontal cortex for decision-making. CPFVM and COF remain important in relation to the amygdala and both contribute to decision-making, although the mechanisms by which it occurs are distinct.

It is postulated that general intelligence in humans is the result of a functional integration between the alert system based on the anterior cingular cortex (ACC) and the executive system based on the dorsolateral prefrontal cortex (CPFDL).

2.4.1. Pleasure and reward: it is formed by dopaminergic neurons from various regions and nuclei mainly by the medial prosencephalic bundle in the nuclei of the hypothalamus. The connection with the septum, the amygdala, areas of the thalamus and the basal ganglia explains the relationship of the brain with pleasure and motivation, as there is also the circuit of punishment, the speciocos. With. Dopamine is closely related to this sense of reward, directly linked to the fact that drug addictions that cause addiction.

2.4.2. Joy: this emotion occurs through dopamine integrated into the substantia nigra of the ventral striatum and the putamen. Dopamine uses opioid and GABAergic receptors in the ventral striatum, amygdala and orbitofrontal cortex. It is noteworthy that the cerebellum may be interconnected with smiles and crying and injuries can directly affect these behaviors and conditions. 
2.4.3. Fear: an amygdala is considered the main structure of the SL, being responsible for the feeling of fear, feelings of threat and danger. Your injury can cause lack of emotionality and recognition of fear. But also, studies have revealed a link between joy and the amygdala being of extreme emotional importance.

2.4.4. Anger: a main structure related to anger and aggressiveness is the hypothalamus, the telencephalon would act by inhibiting such behaviors. According to an area of stimulated hypothalamus we will have different types of aggression, as well as in fear, the amygdala is involved in the feeling of anger as well.

2.4.5. Escape-fighting reactions: by efferent means we have the hypothalamus and the Autonomous Nervous System, presumably linked to hypothalamic projections on the brainstem. By the efferent pathway we have the vagus nerve that takes information to the CNS, where it connects to structures of the forebrain (hypothalamus, amygdala and thalamic regions that control the insula and orbitofrontal cortex) and $\mathrm{p}$. Thus producing sympathetic autonomic response such as increased heart rate and blood pressure, increased blood glucose level, dilated pupils, among others. Which occurs associated with occurrences of CNS effects such as stimuli and tonsils that various responses, where they reflect on the behavior of "struggle or flight", when threatened.

2.4.6. Sadness: it is an emotion that leads us to reflect, being synonymous with joy, and occurs in cortical regions, in various wolves and gyres and also in the amygdala. Sadness is often confused with depression because they have common characteristics, but depression is a pathological disease, associated with neurochemical deficits, thus being more complex and prevailing for simpler than the screened caute that.

2.4.7. Emotion and reason: messages that reach the brain are processed and patterns by means to take structures an emotional meaning, passing through limbic, paralympic, resulting in decision-making. The main structures involved are the occipital visual cortex, an amygdala, hippocampal circuits related to memories and the prefrontal cortex. Another linked structure is the insula lobe, activated when recordings of emotions lived. Thus making it clear that decision-making needs emotional mechanisms previously experienced, creating external responses such as motor and autonomic (ESPERIDIÃOANTONIO, et al., 2021) 


\subsection{Characteristics of personality disorders}

A previous physiology of Borderline personality disorder will be described only as an example standard for understanding the regions of the brain, bringing understanding to behavior. Of these disorders listed in the article, Borderline is more specific as a result of traumatic factors in childhood such as sexual, physical or emotional abuse. However, due to the evidence of symptoms, this also serves as a parameter for the direction of the functions involved in the disturbances.

Disorders reveal adjacent behavior of the regions of the brain where they occur as dysfunctions. Genetic factors act as triggers, traumas and other external factors as drivers and the basic elements of variations in the brain regions involved define the individual's disorder.

\subsubsection{Tonsil}

Brain scans that people with Borderline Syndrome have visibly smaller tonsils than the general population and may even suffer atrophy. The smaller the tonsil, the more hyperactive. This means that when people with BPD experience an emotion, they do so more intensely than the general population, and the "cooling" Periodit takes much longer. Cell losses caused by stress act mainly on the limbic system, causing the retraction of dendritic processes, the inhibition of neurogenesis, and even the death of neurons, such as a dimin volume example. Care That Glucocorticoids Connect to Receivers In Several Areas Of The Brain, As Icecat Example, The Hippocampus and Tonsil, by a Functional Magnetic Resonance Study (fMRI, ), Investigated with a Temporal Evolution And The Locus Effects Of Cortisol On Color : Brain Structures In Adult Humans at Individuals who have suffered sexual abuse in childhood and adolescence, for example, dissipation of the volume of the hippocampus and amygdala, the gray matter of the prefrontal cortex and the corpus callosum.

\subsubsection{Hippocampus}

The hippocampus of individuals with BPD is in a state of continuous hyper-excitation. Uncoordinated and dysfunctional, he always misinterprets as correction and transmits defective messages back to the amygdala. This means that people with this disorder are more likely to consider other people and the world around them as threatening, when this may well not be intention or reality. 


\subsubsection{Hypothalamic-pituitary-adrenal axis}

The hypothalamic-pituitary adrenal axis is primarily responsible for the production of cortisol in the body. Cortisol is a natural chemical released during periods of stress. Different studies that people with BPD have abnormal cortisol levels in the bloodstream. A lot of cortisol production means that stress levels in daily life are always overwhelming and psychologically, resilience and coping difficulties are impaired, because it will chemically break this.

\subsubsection{Prefrontal cortex}

The prefrontal cortex is the pinnacle of human evolution, not only because it is responsible for reason, rationality and decision-making, but because it also inhibits our primordial nature. People with certain disorders have inactive and inefficient prefrontal cortex. This is one of the reasons for some of the characteristic symptoms of Borderline disease, such as impulsivity. Francisco Goy a (apud MÜLLER, 2020) said, the "sleep of reason generates monsters" and, with a dormant prefrontal cortex, with Borderline Personality Disorder they find themselves assaulted by emotions, which make us feel out of control.

\subsubsection{Characteristics of TPH}

The center of attention: discomfort when it is not the center of opinions;

Sexually seductive: sexually inappropriate, provocative or seductive behavior;

Inconstant emotions: an expression of emotions tends to be superficial and change rapidly;

Physical parsence and narcissism: consistently employ physical parency to draw attention to themselves;

Speech Style: the speech style is poor in details; they tend to generalize, and when they speak, they seek to please and / or impress;

Dramatic Behaviors: use self-dramatization and exaggerate their emotions;

Suggestionability: they are easily influenced by other people or places;

Overvaluation of intimacy: they overvalue the level of intimacy in a relationship.

\subsubsection{Characteristics of NPT}

Persistent pattern of grandeur: need for admiration; an exaggerated and unfounded feeling of your own importance and talents; 
Concern about fantasies of unlimited achievements: influence, power, intelligence, beauty or perfect love;

Conviction of specials: feeling of being special, unique and should be associated only with people of the highest caliber;

Admiration: need to be unconditionally admired;

Sensations: of merit, importance, being right, being better than others;

Manipulation: exploitation of others to achieve objective objectives;

Feelings: lack of empathy, envy of others and conviction that others envy them;

Behavior: arrogance and haughtiness.

\subsubsection{Characteristics of TPL}

Fear of abandonment: fear of being alone. When you feel that you are going to be abandoned, the person is angry. Creates impressions of rejections incoherently. Empathy for interest. Frequency of the feeling of emptiness;

Anger: difficulty in emotional control, possibility of intense intense and without justification. Sarcasm, bitterness, anger attack, and can be directed at friends, travel and close people;

Instability: changes of opinion, self-image, values, friends, career abruptly;

Impulsive behavior and self-harm: suicide attempt and correction and self-harm. Betting on gambling and sexual behavior without protection eating compulsively, driving recklessly, substance use and compulsiveness;

Narcissism: sabotages herself when she is about to achieve a goal, so that others have an impression that she is having difficulties as a way to draw attention. They can be charming, fickle and verbally superficial in their efforts to get what they want.

\subsubsection{TPAS characteristics}

Neglect for others: these people can deceive, steal, defraud, exploit and manipulate people;

Emotion: impulsivity, they do not plan with anti-sidence and are usually inconsequential. They can get irritated easily and be aggressive;

Irresponsibility: they may not comply with responsibilities;

Relationship: partner exploitation, selfishness, abuse and exploitation;

Lack of empathy: they are determined not to be intimidated and seek that it is better for themselves at any cost. Indifference to the feelings, rights and suffering of others; 
Narcissism: high opinion of oneself, stubbornness, self-confidence and / or arrogance.

\subsubsection{Characteristics of TPB}

Emotion: imbalance and emotional instability, persistent in displacements, self-image, sense and marked impulsivity;

Fear of abandonment: desperate efforts to avoid abandonment even if it is inconsistent;

Relationship: intense and unstable that oscillate between idealization and devaluation of the other person;

Behavior: gestures or correction of repeated suicide or self-harm as a way to draw attention; stress product;

Rapid mood swings: they can last only a few hours and no more than a few days;

Feeling: feeling of constant emptiness, difficulty controlling anger;

Thoughts: temporary paranoid and / or severe dissociative symptoms triggered by stress; Vulnerable narcissism: a form of narcissism characterized mainly by neuroticism, feelings of shame and introversion. In this case in TPB, this narcissism is seen as grandiose and pathological; sense of law, selfishness, lack of empathy, arrogance and search for attention.

\subsection{Causes}

Consequences of biological, cognitive and social development factors; with the possibility of genetic triggering. Repetition of behavior learned; whether by parents or society, especially in children's phase.

\subsection{Treatment}

The objective article is not addressed but to solve the common behavior in Brazilian society this year 2021. Neurotherapy or psychoconstruction is recommended by the author of this article. Genetic-behavioral-based therapies, using neurotransmitters and psychoanalytic and cognitive therapies as reference. With maintenance of habits, habits and neuroplasticity.

\section{FINAL CONSIDERATIONS}

In our society, provided by social, technological, temporal, educational culture, among others, we are living the phase of dramatic personalities. Histrionic, Narcissistic, Borderline, Antisocial and Borderline are some of them. Deficits in the functions of attention, memory, language, abstraction, behavior planning / sequencing and neuroivory performance are increasingly reported in offices. 
There were propagation of evident behaviors such as: excessive anxiety, selfishness, narcism, egocentrism, denialism, insistence and propagation of false news, less empathy, lack of solidarity or solidarity to call attenuation, lack of exo of compassion, need for fame without argument and coherence, investment in buying likes and followers on the social Behaviors derived from pathological narcissism and the need to seek happiness as if this location is increasingly difficult to achieve.

Society is suffering a derivative of anxiety, for its culture and need for reward. The predominant and essential instinct requires anxiety, which triggers the limbic system, through the hippocampus, amygdala, and more circuits, a solution. Anxiety evokes natural negative memories as a defense mechanism and brings to the prefrontal cortex a reason for a solution. Dopamine, in turn, is also essential in activity, anxiety action so that this can be a search engine for its liberation and the feeling of reward, motivating us to conquer Necessary for us to feed, hunt, plant, harvest, to survive, is also released in common achievements such as likes, acceptance, consumption, among other behaviors that satisfy.

The more constant and intense and intense anxiety, the more human beings enter a negative atmosphere. Linking this to events of discomfort, fear, receipt and change of routine. We have several hypotheses that cause increased anxiety and with it, the need in the body to achieve homeostasis, seeking the release of neurotransmitters from happiness and / or sensations of pleasure. Imagine a line that measures the degree zero in which, below is the negative state and above the positive. Anxiety leads to the negative and constantly a person seeks to exceed zero to reach the positive, and the negative becomes permanent and the positive rare and with oscillations. The body in turn has the need to seek the positive and the more it goes beyond the line, the greater the need to overcome it. Not only dopamine, but our brain, as a circuit, anxiety and the search for well-being involve several neurotransmitters and when deregulated, cause dysfunctions that can be seen in the alteration of regibraises regions. When we analyze the behavior and do not understand its inconsistency, the lack of cognitive perception of the acts, it must change in the behavior also of the brain regions, their neurons and neurons. Disturbed or upset people, as a consequence of this cycle anxiety - instinct - negativity - happiness and its dysfunctions, have changes that prevail emotion and distort reason. The inefficiency of 
the prefrontal cortex derived from this lack of control reveals behavior that harms the person and this, with others, a society.

Brazilians are the most anxious people in the world, according to WHO data from 2019, this is due to conurbation, lack of expectation, social and economic problems, violence, diseases, problems with school education of school parents anxiety and that, linked to technological advancement and the social network, the ingredients that trigger disturbances that can define the future genetics of this society.

With knowledge, the creation of therapies of this type of psychoconstruction and neurotherapy aims to treat the patient according to genetics, personality and behavior. Seeking habits not only through food and physical exercise, but with treatments aimed at neurotransmitters. It also advises an urgent change in the process of school education, of parents, as well as a cultural limit to protect the future of this society.

\section{REFERENCES}

AFONSO, A; et al. Anxiety (Serotonin and GABA). Madness and the control of emotions. Rev. Psicofisiologia , Minas Gerais, v. 1, n. 1 and 2, chap. 5, 1997.

BEAR, MF; CONNORS, BW; PARADISO, MA. Mental disorders. Neurosciences Unraveling the nervous system. Porto Alegre: Artmed, 2ed, 2ed, cap 21, p. 675701, 2006.

BURGDORF J, PANKSEPP J. The neurobiology of positive emotions. Biobehav Rev. Neurosci. 2006; 30 (2): 173-87.

ESPERIDIÃO-ANTONIO, V., et al. Neurobiology of emotions. Arquivos de Psiquiatria Clínica (São Paulo), v. 35, p. 55-65, 2008.

LE DOUX, J. Where the disorders are. The Emotional Brain: the mysterious foundations of emotional life. Rio de Janeiro: Objective, 8ed, chapter 8, p. 206243, 2001

MÜLLER, V. Neurodiagnosis VTM. Innovative Treatment - Personality Disorders (2020). Available at: https://vtmneurodiagnostico.com.br/2020/07/22/transtornoda-personalidade-borderline-eo-cerebro- tratamentos-inovadores/, Accessed on: 12 Jul. 2021. 